\title{
O Plano Nacional de Educação: algumas questões para debate ${ }^{1}$
}

\section{Brazilian National Plan for Education: some issues to debate}

\section{Romualdo Portela de Oliveira²}

\section{Resumo}

O presente artigo analisa os principais desafios presentes na elaboração do Plano Nacional de Educação. Enfatiza a importância de mecanismos de acompanhamento e controle que possibilitem uma auditoria da implantação do plano e das eventuais correções de rumo. Entre as principais questões em disputa, destaca-se a importância de se construir mecanismos democráticos de gestão do sistema, ao mesmo tempo em que sinaliza a importante batalha em torno da necessidade de ampliação dos recursos investidos em educação, chamando a atenção para a timidez da proposta apresentada pelo Governo em desacordo com o aprovado na Conae.

Palavras chave: Plano Nacional de Educação; Gestão democrática de sistema; Financiamento da educação; $10 \%$ do PIB.

\begin{abstract}
This article analyzes the main challenges in the development of Brazilian National Education Plan. It emphasizes the importance of monitoring and control mechanisms that turn enable auditing actions over the plan and turn possible any necessary correction. Between the main issues in dispute, highlights the need to build democratic mechanisms for educational system administration, while it signals an important battle over the need to expand the resources invested in education, drawing attention to the timidity of the Government proposal at odds with the approved resolutions at Conae.

Keywords: Brazilian Education National Plan; Educational System Democratic Administration; Education financing; 10\% GNP for education.
\end{abstract}


Uma das fragilidades da educação na sociedade brasileira contemporânea é que sua defesa tem sido feita apenas pelos trabalhadores da educação. Enquanto não rompermos esse isolamento social, conseguindo atrair outros setores da população para a defesa da importância social da educação no conjunto das políticas públicas, estaremos indefesos contra as investidas de administradores inescrupulosos, que apenas declaram a educação como uma prioridade em momentos de eleição, mas que não transformam essa declaração em ações efetivas, particularmente aquelas que dizem respeito aos gastos públicos. Meu orientador de mestrado, o professor José Carlos de Araújo Melchior, ensinou-me, há muitos anos, que descobrimos a prioridade de um governo, não pelo discurso que faz, mas quando olhamos os seus gastos.

Isso é particularmente importante no momento em que discutimos um novo Plano Nacional de Educação (PNE), precedido por um processo democrático de discussão que envolveu mais de três milhões de pessoas, atingiu todos os quadrantes do país e culminou com uma Conferência Nacional de Educação (Conae) com mais de 4 mil participantes, envolvendo, de forma inédita, a participação governamental em conjunto com a sociedade civil. Entretanto, para espanto de todos, o Governo Federal, ao encaminhar sua proposta de PNE ao Congresso Nacional, desconsiderou as principais formulações aprovadas na Conae e se submeteu aos ditames de uma política de controle das contas públicas, tímida, imediatista e incapaz de compreender os imensos desafios que se apresentam ao país nos próximos anos, em síntese, não atribuindo à educação a importância que esta tem no processo de construção da cidadania e de preparação do país para se inserir em condições mais favoráveis nas difíceis condições de competitividade da economia do século XX.

Em vista disso, entendo que, em torno do PNE, travaremos disputa fundamental, na qual definiremos o país que queremos nas próximas décadas.

AodiscutirmosumPlanoNacional deEducação, o primeiro ponto a ser ressaltado é a necessidade de ter compromisso com sua implementação, por meio de mecanismos de acompanhamento, sob pena de ser desconsiderado como elemento norteador da política educacional nos próximos anos. Neste particular, parece-me adequado perseguir com ênfase a implantação de suas metas. Isso significa romper com várias de nossas fragilidades no tratamento das questões educacionais. É uma questão política tornar o Plano o instrumento de alinhamento da política educacional, a bússola que dá a diretriz para as ações na área. Isso contraria nossa tradição. Até hoje, nenhum plano de educação no Brasil saiu do papel. Nessa perspectiva, não basta apenas que se aprove isso ou aquilo. É necessário que tenhamos clareza da forma como as temáticas aprovadas serão efetivadas, tanto no âmbito do financiamento quanto da gestão. Só o acompanhamento cidadão garante que o plano venha a se tornar realidade e, mais do que isso, que ele sobreviva a eventuais mudanças nos postos dirigentes do sistema educacional.

Assim, a forma de tomada de decisões, fora dos momentos episódicos de elaboração das mesmas, torna-se uma questão extremamente importante. O dilema da estrutura de tomada de decisões é o seguinte: como a base pode interferir na definição das políticas educacionais de maneira mais efetiva? A resposta que me ocorre é a necessidade de construção de organismos mais estáveis de participação da base, que sejam incorporados ao funcionamento regular do sistema de ensino. Tentar responder a esse dilema, nos permite uma breve digressão sobre estrutura de tomada de decisões em uma perspectiva democrática.

Durante o processo de elaboração da Lei de Diretrizes e Bases da Educação Nacional (LDB), Lei 9394, de 1996, as concepções de democracia em nível de sistema se objetivaram em três propostas: a) a constituição de um Fórum Nacional de Educação; b) uma proposta de composição do Conselho Nacional de Educação a partir da representação de diferentes grupos e categorias profissionais e; c) a realização de Conferências Nacionais de Educação que ajustariam suas metas e o ritmo de sua implantação.

O primeiro deles consistiria em um organismo, com representação de organizações da 
sociedade civil, com a finalidade de acompanhar a implementação do PNE. Uma espécie de auditor da implantação do Plano.

O segundo seria o organismo responsável pela normatização legal do sistema, com composição definida a partir da representação de diferentes grupos e setores, como representante dos professores das redes públicas deeducação básica, dos professores do ensino superior, representantes dos pais e, como os proprietários de escolas etc. Entretanto, tal equacionamento não dá conta de responder ao desafio da gestão democrática no âmbito de sistema. O problema é explicitar como os membros da comunidade de cada escola terão voz nos processos de formulação de políticas educacionais. A resposta mais contundente a esta proposição foi dada pela experiência da gestão Luiza Erundina na cidade de São Paulo, por meio da implementação dos Conselhos Regionais de Representantes de Conselhos de Escolas (CRECES). Tais organismos, com poder deliberativo, situados nos níveis intermediários do sistema, seriam o embrião da constituição de um Conselho Municipal de Educação, composto por representantes de cada um desses organismos regionais. Assim, cada uma delas, as instâncias intermediárias e a central, seriam constituídas por representantes dos níveis anteriores.

O terceiro corresponde às Conferências com representação de base que avaliariam - Plano e proporiam revisão e ajuste de suas metas, com periodicidade de reunião maior (quinquenal, por exemplo).

Com esses encaminhamentos, esperava-se equacionar a temática da gestão do sistema e avançar na construção de um Sistema Nacional de Educação.

Feitas estas considerações iniciais, passarei rapidamente pelos principais eixos de discussão do PNE, buscando, ainda que de maneira não exaustiva, explicitar os problemas e desafios envolvidos.

\section{Sistema Nacional de Educação - regime de colaboração}

O primeiro tema que gostaria de abordar, no âmbito do debate sobre o PNE, diz respeito à proposta do Sistema Nacional de Educação. Como se sabe, a ideia de um sistema nacional encontra-se em oposição à situação atual de existência de três sistemas, o federal, o estadual e o municipal. Os problemas de fundo a serem enfrentados são:

i. Como garantir condições de igualdade de atendimento a todos os cidadãos em um país cuja estrutura federativa (e a consequente distribuição de impostos) permite que alguns estados gastem, por aluno, mais de quatro vezes que outros e mesmo após os atuais mecanismos de complementação previstos no Fundeb, continuamos com estados gastando por aluno o dobro de outros?

ii. Como garantir, minimamente, uma uniformidade normativa para o conjunto do país?

Comecemos com a questão da desigualdade. Para reverter essa desigualdade seria necessário implementar políticas redistributivas a partir do governo federal. Para isso, o governo federal precisaria ter uma política resoluta de combate à desigualdade regional, com condições políticas de efetivá-la.

Uma forma de atingir esse objetivo seria uma reforma tributária que permitisse a transferência de recursos dos Estados e Municípios mais ricos para os mais pobres. Tal alternativa padece de uma inviabilidade política difícil de se enfrentar. Mesmo as modestas propostas de reforma tributária, que procuram alterar ou minimizar o quadro atual, são sistematicamente bombardeadas no âmbito do Poder Legislativo. A alternativa tem sido especificar algumas políticas de redução de desigualdades no âmbito da ação da União. Um exemplo é a proposta de complementação da União ao Fundef. Nesse caso, tomando como referência uma média de gasto/aluno possível (definida a partir da divisão dos recursos disponíveis pelo número de alunos do ensino fundamental), a União complementaria os estados que não atingissem a média nacional até este valor médio. Assim, essa média nacional passaria a ser o novo valor mínimo. Este procedimento teria um forte componente redistributivo. O problema é que nos anos de vigência do Fundef, 
o dispositivo não foi cumprido pelo governo federal, que se esquivou dessa responsabilidade por meio do artifício do subdimensinamento da média nacional. O mecanismo engendrado pelo Fundeb segue o mesmo pressuposto, ainda que seja mais modesto. Neste caso, depois do ano de 2009, quando se completou a transição do Fundef ao Fundeb, o montante da complementação da União ao mesmo tempo estaria limitado a 10\% do total de recursos do Fundo. Tais iniciativas, na impossibilidade de uma alteração mais estrutural da desigualdade regional, são alternativas possíveis. Entretanto, não constituem um Sistema Nacional que além de apontar para um gasto mais equânime, trabalharia com a perspectiva de uma normatização comum. Tal alternativa não se viabiliza, posto que existe a disposição legal da autonomia dos entes federados. Ou seja, ainda que defensável, o sistema nacional tem apenas o caráter de propaganda, de dever ser, mas não se encontra, de fato, na perspectiva da viabilidade política.

Resta-nos, portanto, indagar se e em que medida seria possível romper com o isolamento atualmente observado dos sistemas de ensino entre si?

A legislação prevê o 'regime de colaboração's. Esperava-se o desenvolvimento de mecanismos de cooperação entre esferas diferentes. Entretanto, ante a pequena extensão que tais parcerias alcançaram, concluiu-se que haveria necessidade de uma lei específica para regulamentar o "regime de colaboração". Tal iniciativa parece-me pouco produtiva. Não há como obrigar entes federados autônomos a colaborarem entre si. A alternativa que resta nesse quadro jurídico é a da responsabilização e a previsão de punições pela omissão, mas não há elementos para impor a colaboração. No plano político, os níveis centrais podem induzir comportamentos pelo mecanismo das transferências voluntárias de recursos. De toda forma, é preciso não esquecer que, se não houver disposição das partes, não há mecanismo que force uma colaboração.

30 artigo 211 da Constituição Federal de 1988 estabelece que: "A União, os Estados, o Distrito Federal e os Municípios organizarão em regime de colaboração seus sistemas de ensino". (grifo meu)
A perspectiva que me parece mais promissora é tomar como referência as experiências de colaboração que vêm sendo realizadas, ainda que limitadas, e pensar formas de ampliá-las ou de difundi-las para outras regiões (OLIVEIRA \& MENEZES, 2010).

Considero que a temática da colaboração entre os entes federados encerra dois desafios de grande importância:

i. Como diminuir a desigualdade de condições de acesso ao sistema de ensino?

ii. Como fazer para que a ação pública na área de educação seja implementada com maior colaboração entre a União, os Estados e os Municípios?

\section{Acesso}

Ainda que tenhamos alcançado praticamente a universalização do acesso ao ensino fundamental, aumentando seus níveis de conclusão e ampliado o ensino médio para mais de nove milhões de matriculados no início desta década, permanecem grandes e graves problemas de acesso, tendo inclusive a matrícula total desta etapa retrocedido nos últimos anos para aproximadamente 8,3 milhões, sem falar na pequena cobertura da educação infantil, 40\% do grupo etário de 0 a 5 anos, atingindo apenas 20\% na creche.

No caso do ensino fundamental, localizamse regiões (basicamente no Nordeste Rural e na periferia das grandes cidades), onde há falta de vagas. No ensino médio, a redução da matrícula total que observamos nos últimos anos é preocupante. Tal quadro é agravado pelo fato de termos apenas 55\% de matrícula líquida, ou seja, metade da população de 15-17 anos encontra-se no Ensino Médio. Isto significa que a outra metade ou ainda não concluiu o ensino fundamental ou encontra-se fora do sistema escolar. Tanto uma situação como a outra, representam formas de exclusão preocupantes no momento em que ampliamos a obrigatoriedade até os 17 anos (Emenda Constitucional n 59/2009).

Entretanto, na Educação Básica, o maior problema de acesso encontra-se na educação infantil. Nesta etapa, atualmente, atende-se menos de 40\% do grupo etário. Ou seja, estamos 
muito longe de garantir esse direito a toda população. Tal carência de vagas é mais grave na creche, que atende a faixa etária de zero a três anos, com apenas 20\% de cobertura em relação à população potencial. É certo que nem toda a população que poderia estar na creche procura por ela, posto que para o indivíduo não é obrigatória, mas também é certo que temos um contingente muito grande da população que demanda uma vaga e não é atendido. Isto tem feito com que muitos municípios recorram ao lamentável expediente do convênio. Ainda que haja um debate acerca da privatização, a razão principal pela qual se recorre ao convênio não é ideológica, mas pragmática. Recorrese a esta alternativa porque é mais barata que a oferta direta. Dizendo de outra maneira, as creches conveniadas oferecem um serviço de qualidade limitada, o qual se fosse ofertado nas mesmas condições de (baixa) qualidade pela administração pública diretamente, haveria muitas ações judiciais por oferta de educação de baixa qualidade ou em condições precárias. Logo, urge equacionarmos a questão do atendimento de qualidade para a educação infantil por meio do atendimento direto pelo Poder Público.

Em síntese, podemos dizer que as questões deste item são:

i. Como fazer para garantir a expansão do sistema, garantindo vagas na educação infantil pública para todos que a demandarem?

ii. Como garantir a universalização definitiva do acesso e sucesso no Ensino Médio?

Finalmente, a perspectiva de universalização da conclusão do Ensino Médio coloca-nos uma questão importante acerca do "desenho" do sistema de ensino. O que fazer? Buscar vagas para todos no Ensino Superior? Introduzir alguma possibilidade de terminalidade da formação inicial ao final do Ensino Médio ou em cursos profissionalizantes após a conclusão do Ensino Médio? Ambas as alternativas implicam no alargamento do sistema, quer seja o de Ensino Superior quer seja o de Formação Profissional. Coloca-se, assim, uma complicada questão: como expandir o sistema de ensino, levandose em conta as disposições apresentadas por nossos governantes no que diz respeito à ampliação dos gastos públicos em educação?

\section{Qualidade da Educação}

Outro aspecto importante do PNE diz respeito à qualidade. Ainda que tenhamos avançado no debate acerca dessa complexa questão, longe estamos de conseguir algum acordo. A formulação que me parece ajudar no debate é a seguinte: qual o conceito de qualidade que devemos adotar de modo a que, no limite, possamos ir à justiça para garanti-la para todos como forma de cumprir o dispositivo constitucional que afirma ser um princípio a garantia de um padrão de qualidade?

Temos nos debatido com duas formulações a respeito. De um lado, o IDEB, Índice de Desenvolvimento da Educação Básica e, de outro, a de garantia de um gasto mínimo por aluno, sintetizada na proposta de Custo Aluno Qualidade inicial (CAQi). O Ideb estabelece como padrão de qualidade uma composição entre aprovação e resultado nas avaliações em larga escala, e que deriva em metas sistêmicas que fariam com que, em 2022, nos aproximássemos dos resultados obtidos pelos países da OCDE. Ainda que considere o Ideb uma importante contribuição à formulação e avaliação de políticas públicas na área, não o considero um indicador de qualidade, mas de resultados. A diferença é importante. O Ideb retrata dois resultados desejáveis, quais sejam: que os alunos atinjam proficiência adequada em matemática e linguagem e que todos sejam aprovados. Entretanto, os objetivos da educação são mais amplos do que isso. O nosso padrão de qualidade não pode se restringir ao que se pode medir (seria a substituição dos fins pelos meios), isto significaria simplificar o alcance social do que esperamos da educação. Tenho trabalhado com a idéia de que um padrão de qualidade deveria contemplar três dimensões, os insumos (ou condições), os resultados e os processos.

A materialização da primeira dimensão é de mais fácil apreensão e é em sua definição que conseguimos mais acordo. Uma educação de qualidade pressupõe que sejam garantidas a todos, condições mínimas de funcionamento das escolas. Sua tradução no debate contemporâneo 
seria a idéia do Custo-Aluno Qualidade inicial (CAQi) elaborado pela Campanha Nacional em Defesa do Direito à Educação.

A segunda dimensão pode ser formulada pela seguinte indagação. Quais resultados esperamos do processo educativo? Que abrangência eles deveriam ter? Como ponto de partida, o Ideb é uma contribuição importante. O que precisaríamos discutir é se ele é um indicador suficiente de resultados esperados. Se sim, bastaria definirmos a meta a ser alcançada como expressão da garantia da qualidade para todos. Se não, teríamos de responder quais elementos deveriam ser agregados a esse indicador de resultados? De toda forma, não se pode perder de vista a busca por indicadores operacionais indicadores operacionais que possam ser exigidos como expressão da qualidade garantida a todos. Isto implica, necessariamente, aceitar algum esquematismo. Isso é aceitável, desde que não se desvirtue, por conta de dificuldades operacionais, o objetivo da educação que se deseja. Não se pode inverter a hierarquia de valores. Dada a concepção de qualidade que desejamos, desenvolvem-se os mecanismos para medi-la e não reduzirmos nossa concepção de qualidade ao que se consegue medir mais diretamente.

Finalmente, a terceira dimensão é a mais complicada. Em educação os processos não são irrelevantes. Nosso padrão de qualidade não pode referenciar-se apenas na busca de resultados, posto que, concebemos a educação como algo mais amplo do que obter bons resultados em avaliações em larga escala. Se não atentarmos para isto, estaríamos reduzindo nosso processo educativo ao que se chama de "educar para o teste", também não podemos reduzi-la a uma relação "adequada" entre insumos e resultados.

Há elementos do processo educativo, bem como suas práticas, que são valores a serem buscados, independentemente de aumentarem ou não o resultado nas testagens. Ideias como educar para a paz, para a tolerância, para a democracia e a participação, entre outras, são objetivos inegociáveis do sistema educacional democrático. Transformar esses conceitos em indicadores que "dialoguem" com as demais dimensões é nosso desafio teórico e político.

\section{Financiamento da Educação}

Dadas as considerações feitas no item anterior, o estabelecimento de um custo aluno qualidade inicial implicará na necessidade de se gastar mais em educação. Vale lembrar que se queremos dar um salto na qualidade na educação é iniludível a necessidade de ampliarmos o gasto público nessa área.

Nessa perspectiva é instrutivo lembrarmos que na elaboração do PNE, 1991-2010, a sociedade civil organizada propôs destinar 10\% do PIB à educação. No processo de discussão, tal meta foi reduzida para 7\%. Mesmo esta, mais modesta, foi vetada pelo então Presidente Fernando Henrique Cardoso e apesar de haver prometido cumpri-la na sua campanha de 2002, também não foi cumprida pelo Presidente Lula. Ao contrário, o gasto em educação em relação ao PIB manteve-se em torno de $4 \%$ até 2008 , sofrendo acréscimo para 4,7\% apenas em 2009 , atingindo 5\% em 2010.

Entendo que aqui se jogará o sentido último do futuro PNE. Estabelecer metas, objetivos, expressões de desejo e de carências é fácil. Difícil é criar as condições para que os problemas sejam resolvidos. Nessa medida, a necessidade de gastarmos mais com educação deve se objetivar em uma formulação precisa. Não me parece haver argumentos razoáveis para não retomarmos a bandeira dos 10\% do PIB, prevendo-se um acréscimo paulatino do gasto (digamos $1 \%$ ao ano), até se atingir esse percentual.

Entretanto, mais importante do que formular essa meta é pensarmos na forma de se conseguir isso. Certamente não será com pouca luta social.

\section{Atratividade, Formação e Retenção dos Profissionais do Magistério.}

Nesta breve exposição, não poderia deixar de discorrer sobre a questão do magistério. Isto se deve, de um lado, ao seu inegável sentido estratégico, pois não se pode dar um salto na qualidade do sistema educativo sem o aumento da efetividade do magistério. De outro lado, é necessário abordar o tema pelo perigo que algumas leituras dessa importância têm induzido. Há no debate educacional contemporâneo, no 
Brasil, uma tendência de, concomitantemente ao reconhecimento da importância do magistério, culpabilizá-lo por todas as mazelas da educação. Isto, além de injusto é um equívoco. Evidentemente, este movimento tem um claro sentido conservador, mas não é o caso de discutir isso nos limites deste texto. O que importa é que a resposta que decorre dessa culpabilização é equivocada. A mais comum é introduzir mecanismos de remuneração por mérito. Tais propostas, além das dificuldades técnicas referentes à medida, não têm evidência empírica de sua correção, traduzindo apenas argumentos ideológicos de competitividade, sustentados a priori por seus propositores.

A elaboração do PNE é um momento importante para equacionarmos adequadamente a questão. Segundo entendo, e temos muitas evidências empíricas disso, emanada da experiência de outros países, a melhoria da qualidade do magistério só será alcançada se articularmos quatro dimensões: a atratividade, a formação, a retenção em serviço dos melhores profissionais e o desenvolvimento de mecanismos de avaliação do magistério com capacidade de induzir melhorias no sistema de ensino.

Em primeiro lugar, deve se tornar o magistério uma profissão mais atrativa no Brasil, de modo a que esta passe a ser levada em conta como uma alternativa plausível de opção profissional para que tenhamos os melhores alunos do ensino médio. Isso se consegue, em primeiro lugar, com melhoria substantiva nos salários. Nessa perspectiva, a defesa do piso nacional, nos termos em que foi aprovado no Congresso Nacional é um importante início de conversa. Mas a valorização profissional do magistério não se restringe ao salário. Temos necessidade de discutir a fundo algumas vantagens associadas à profissão: condições de trabalho, férias, aposentadoria, planos de carreira e questões mais subjetivas, que dizem respeito à valorização social da profissão. Em nossa sociedade, professor é uma profissão menosprezada, ridicularizada. Faz parte desse achincalhe, por exemplo, a existência de programas humorísticos na televisão que ridicularizam o papel do professor e o ato de educar (não há nada similar com os médicos ou advogados), a adoção do termo "professor" para designar, até mesmo, técnicos de futebol, entre outros exemplos.

A questão da formação inicial é a segunda dimensão a ser enfrentada. Hoje temos um impasse sobre o sentido e a abrangência da formação inicial necessária à garantia de melhora na escolarização para a população (GATTI, 2009). De toda forma, é razoável aceitarmos a ideia de que o modelo vigente é insuficiente.

A terceira dimensão diz respeito à retenção dos bons profissionais em exercício. Tal necessidade é agravada pelo fato de, nos últimos 25 anos, já termos formado mais professores do que o número total de postos de professores existentes no país. O problema é que, por não conseguirmos reter a todos no magistério, temos hoje, em exercício, um percentual não desprezível de profissionais sem a devida formação. A lição que se depreende da experiência de outros países é que necessitamos de uma profissão que pressuponha, em primeiro lugar, um salário inicial alto e, em segundo, uma concepção de carreira na qual o bom profissional possa progredir sem deixar de ser professor, ou seja, com a certeza de que o salário crescerá ao longo do tempo. As implicações dessa formulação são imediatas. É preciso pagar melhor os professores, construir carreiras, em que a progressão funcional mantenha o bom profissional como professor.

Finalmente, há necessidade de desenvolvermos mecanismos de avaliação docente que induzam a constante melhoria de seu trabalho, ao mesmo tempo em que reforcem a ideia de que tal trabalho só será bem sucedido se for coletivo. Isso nos desafia a elaborar proposta de avaliação docente que supere as insuficiências da das avaliações baseadas apenas nos resultados dos alunos em provas sistêmicas.

\section{Conclusão}

Gostaria de concluir explicitando uma questão para a qual devemos atentar à medida que avança o debate em torno do PNE. Sempre que somos chamados a discutir educação no Brasil, dada à amplitude de nossas carências, somos tentados a elencar uma infinidade de 
reivindicações e nos tornamos, por essa escolha, incapazes de hierarquizar prioridades e dedicar o devido tempo às formas de operacionalização das mesmas.

Assim, creio que com o aprofundamento dos debates, devemos escolher um pequeníssimo número de questões fundamentais e procurar costurar o leque mais amplo possível de alianças políticas em torno das mesmas. Nesse processo, devemos dedicar grande atenção ao debate em torno das formas de garantir essas reivindicações fundamentais. É com esse lembrete que gostaria de concluir. A meu ver, daremos um salto histórico se conseguirmos unificar a sociedade civil em torno de duas ou três grandes bandeiras. Arriscaria escolher uma bandeira síntese para o financiamento, algo como $10 \%$ do PIB para a educação e uma concepção de gestão democrática para o conjunto do sistema. Se conseguirmos isso, teremos avançado. Se não, teremos apenas repetido nossa triste história, elencaremos reivindicações, mas não criaremos as condições para alcançá-las e o Plano Nacional de Educação daí resultante estará destinado, como os que o antecederam, à crítica implacável das traças.

\section{Referências Bibliográficas}

GATTI, Bernadete Angelina (Coord.). Professores do Brasil: impasses e desafios. Brasília: UNESCO, 2009.

OLIVEIRA, Romualdo Portella de; SANTANA, Wagner. Educação e federalismo no Brasil: combater as desigualdades, garantir a diversidade, organizado. Brasília: UNESCO, 2010. 